\title{
The use of intraoperative triggered electromyography to detect misplaced pedicle screws: a systematic review and meta-analysis
}

\author{
Anthony L. Mikula, BS, ${ }^{1}$ Seth K. Williams, MD, ${ }^{2}$ and Paul A. Anderson, MD $^{2}$ \\ University of Wisconsin School of Medicine and Public Health; 'Department of Orthopedics and Rehabilitation, School of \\ Medicine and Public Health, University of Wisconsin, Madison, Wisconsin
}

\begin{abstract}
OBJECT Insertion of instruments or implants into the spine carries a risk for injury to neural tissue. Triggered electromyography (tEMG) is an intraoperative neuromonitoring technique that involves electrical stimulation of a tool or screw and subsequent measurement of muscle action potentials from myotomes innervated by nerve roots near the stimulated instrument. The authors of this study sought to determine the ability of tEMG to detect misplaced pedicle screws (PSs).

METHODS The authors searched the US National Library of Medicine, the Web of Science Core Collection database, and the Cochrane Central Register of Controlled Trials for PS studies. A meta-analysis of these studies was performed on a per-screw basis to determine the ability of tEMG to detect misplaced PSs. Sensitivity, specificity, and receiver operating characteristic (ROC) area under the curve (AUC) were calculated overall and in subgroups.

RESULTS Twenty-six studies were included in the systematic review. The authors analyzed 18 studies in which tEMG was used during PS placement in the meta-analysis, representing data from 2932 patients and 15,065 screws. The overall sensitivity of tEMG for detecting misplaced PSs was 0.78 , and the specificity was 0.94 . The overall ROC AUC was 0.96. A tEMG current threshold of 10-12 mA (ROC AUC 0.99) and a pulse duration of $300 \mu \mathrm{sec}$ (ROC AUC 0.97) provided the most accurate testing parameters for detecting misplaced screws. Screws most accurately conducted EMG signals (ROC AUC 0.98).
\end{abstract}

CONCLUSIONS Triggered electromyography has very high specificity but only fair sensitivity for detecting malpositioned PSs.

http://thejns.org/doi/abs/10.3171/2015.6.SPINE141323

KEY WORDS electromyography; EMG; tEMG; triggered; neuromonitoring; pedicle screws; technique

I NSERTION of instruments or implants into the spine carries a risk for injury to neural tissue. For example, transpedicular screw fixation has been associated with a rate of permanent nerve root injury of $2.3 \%{ }^{11}$ and with misplaced pedicle screw (PS) rates of $1.7 \%{ }^{26}$ to $20 \% .{ }^{23}$ Calancie et al. ${ }^{4}$ have described a novel technique, stimulus-evoked (triggered) electromyography (EMG), which involves electrical stimulation of a tool or screw and subsequent measurement of muscle action potentials from myotomes innervated by the nerve roots near the stimulated instrument. Measurement of a muscle action potential resulting from a low stimulating current below a set threshold theoretically indicates a breach in cortical bone or close proximity of surgical instrumentation to nerve roots.

The threshold is the minimum amount of current re- quired to elicit a measurable action potential in the myotome innervated by nearby nerve roots. This threshold was originally used to ensure safe placement of PSs during lumbosacral spine fixation. In addition to lumbar PS placement, ${ }^{2,24,25,38,42}$ the technique has been used in thoracic $^{3,7,31,34,36}$ and cervical ${ }^{8,15}$ PS fixation, and for cervical spine lateral mass screw ${ }^{8}$ and iliosacral screw ${ }^{22}$ fixations.

The reported effectiveness of triggered EMG (tEMG) varies widely and differs according to procedure, anatomical level, electrical current threshold, specific surgical tool conducting the current, and pulse duration. On the basis of our experience, we believe that tEMG has significant limitations for detecting misplaced PSs. In this study, we therefore performed a systematic review and meta-analysis to determine the reliability of tEMG for detecting misplaced PSs.

ABBREVIATIONS AUC = area under the curve; EMG = electromyography; PS = pedicle screw; ROC = receiver operating characteristic; tEMG = triggered EMG. SUBMITTED December 28, 2014. ACCEPTED June 16, 2015.

INCLUDE WHEN CITING Published online December 11, 2015; DOI: 10.3171/2015.6.SPINE141323. 


\section{Methods}

\section{Search Criteria}

The computerized databases of the US National Library of Medicine, the Web of Science Core Collection, and the Cochrane Central Register of Controlled Trials were used. The following search terms and strategy were used: (electromyography OR EMG) AND (stimulusevoked OR stimulus OR triggered) AND (spine OR spinal) AND intraoperative. The references of studies whose titles suggested they were relevant for this study were manually searched for additional articles. Only articles with full text in English were included. Articles were excluded when they did not address our research question (38 articles), had overlapping data (2 articles), represented animal studies (4 articles), or did not contain the quantifiable data we sought ( 15 articles). Twelve authors were contacted via email to retrieve unpublished data, and 3 of these authors responded.

\section{Data Collection}

The following data were analyzed: study type, procedure type and level, patient sample size, patient age, number of PSs, surgical tool conducting the tEMG current, current threshold used, type of pulse, pulse duration, definition of screw malposition, and reference standard for determining tEMG utility.

The following study outcomes were evaluated: truepositive, false-positive, true-negative, and false-negative detections; reported receiver operating characteristic (ROC) area under the curve (AUC); outcome being measured; neurological complications; and effects of tEMG signals on intraoperative action by the surgeon. These data were either directly taken from the studies when reported or calculated from raw data with the following method: true positives were instances in which a tEMG signal was detected when the stimulating current was below the set threshold and a misplaced screw was present; false positives had a tEMG signal with a current below the threshold and no misplaced screw present; true negatives had a tEMG signal with a current above the threshold and no misplaced screw present; and false negatives had a tEMG signal with a current above the threshold and a misplaced screw present.

\section{Quality Assessment Method}

The quality of the methods in each study was assessed with the Downs and Black checklist, ${ }^{10}$ which measures the method quality of both randomized and nonrandomized studies. This checklist has a high internal consistency (Kuder-Richardson Formula 20 value $=0.89$ ) and high test-retest $(r=0.88)$ and interrater $(r=0.75)$ reliabilities. ${ }^{10}$ It encompasses 27 items, with each item requiring a binary "yes" or "no/unable to determine" response, scored as 1 or 0 , respectively, except for Item 5, which is scored 2, 1 , or 0 for a response of "yes," "partial," or "no," respectively. For the purposes of this review, Item 27 was modified according to methods reported in previous studies: $:^{14,21}$ either 1 or no point was awarded, depending on whether or not a study had performed a power calculation or sample size calculation. This scoring method produces a modified maximum score of 28 for a quality index, with a higher score reflecting a higher quality of a study's methods.

The Downs and Black checklist also assigns subscale scores for parameters such as reporting, external validity, internal validity (bias), internal validity (confounding or selection bias), and power. A risk of bias statement was also assessed with this checklist, following methods used in other studies. . $^{39,43}$

\section{Statistical Analysis}

All statistical analyses were performed using MetaDisc statistical software Version 1.4 (Unit of Clinical Biostatistics, Ramón y Cajal Hospital, Madrid, Spain). ${ }^{44}$ Subgroup analyses were performed only when at least 3 studies were available. The analyses were performed on a per-screw basis. Sensitivity, specificity, and the ROC AUC were calculated. The ROC is a curve that is obtained by plotting 1 minus specificity on the $\mathrm{x}$-axis and sensitivity on the y-axis. The AUC of this plot measures the diagnostic accuracy of the test on a 0 -to- 1 scale, with a higher number indicating a more accurate test when sensitivity and specificity are optimized. Sensitivity and specificity varied according to tEMG thresholds with sensitivity increasing and specificity decreasing with higher thresholds.

Subgroup analyses included current threshold, pulse duration, the surgical tool used to conduct the electrical current, and spinal level of the procedure. Heterogeneity among the pooled studies was assessed with the $\mathrm{I}^{2}$ statistic, which is a quantitative measure of the amount of study heterogeneity. The $\mathrm{I}^{2}$ has a maximum of $100 \%$, and $\mathrm{I}^{2}$ values of $25 \%, 50 \%$, and $75 \%$ were considered indicative of low, moderate, and high heterogeneity, respectively. ${ }^{13} \mathrm{~A}$ sensitivity analysis was performed by eliminating a single study one at a time and examining whether an appreciable (i.e., $\geq 10 \%$ ) change was observed in sensitivity, specificity, or ROC AUC.

\section{Results Literature Search Results}

The initial literature search was conducted between May 26, 2014, and June 6, 2014. In total, 74 citations were retrieved, relevant articles of which had their references hand searched, which identified another 11 articles; 38 of the studies (45\%) were excluded on the basis of the title and abstract. The remaining 47 studies (55\%) were fully reviewed, and 21 of these studies (45\%) were excluded because they had overlapping data, were animal studies, or did not contain quantifiable data that were relevant for this study. The remaining 26 studies $(55 \%)$ were used for the systematic review, 18 of which (69\%) contained relevant medical data that were included in the meta-analysis (Fig. 1).

\section{Quality Assessment of Studies Included in Systematic Review and Meta-Analysis}

The quality index score of the studies included in the systematic review ranged from 11 to 22 , and the average score was 17.3 (SD 2.7) (Table 1). A study with a quality index score of 19-22 was defined as having high quality, 15-18 as having moderate quality, and 11-14 as having 


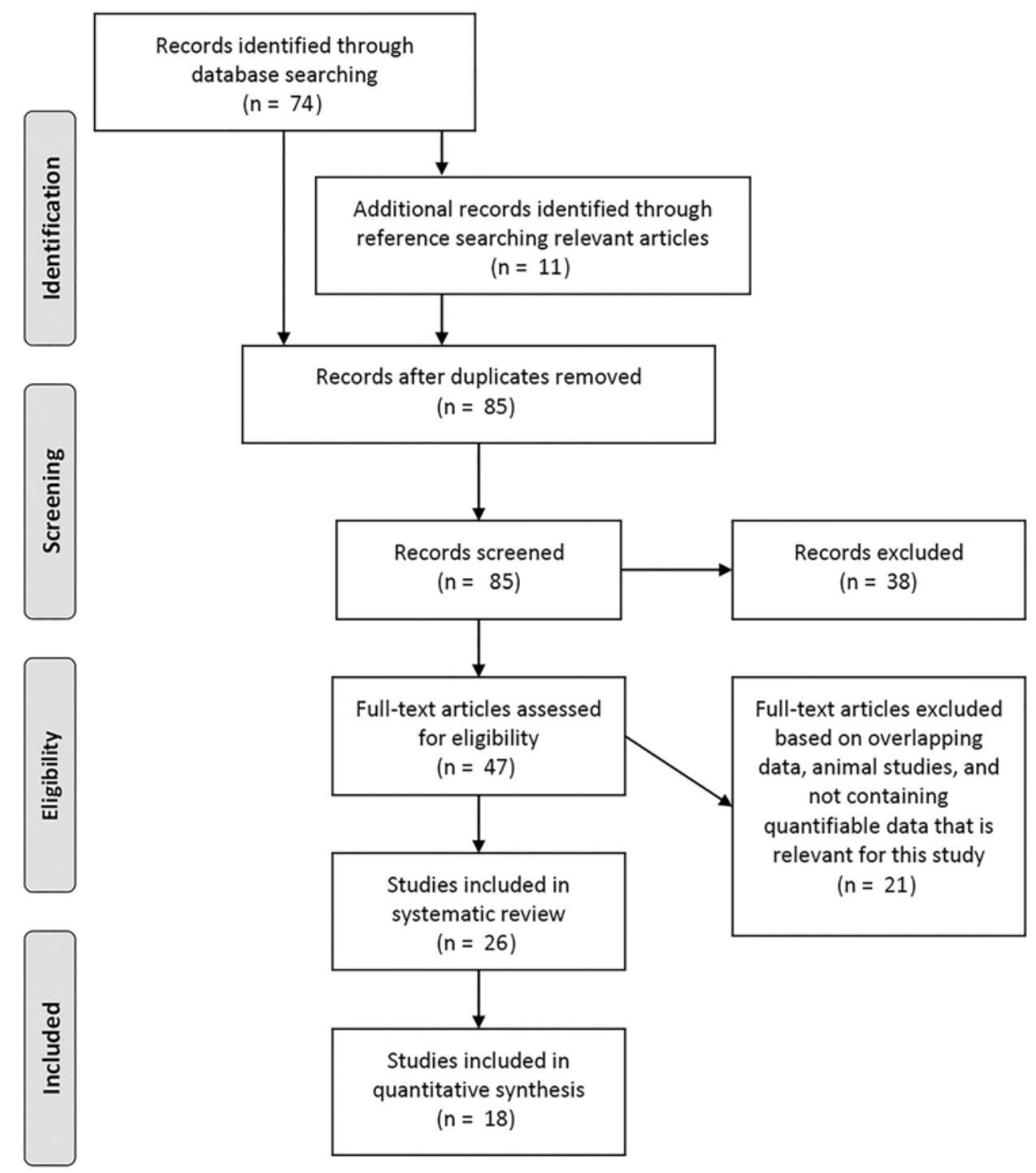

FIG. 1. Flowchart showing the sequence and results of the literature search conducted in this study.

poor quality. There were $8(31 \%)$ high-quality, $15(58 \%)$ moderate-quality, and $3(12 \%)$ low-quality studies. The studies included in the meta-analysis had an average score of 17.2 (SD 2.4), and we included 5 (28\%) high-quality, 11 $(61 \%)$ moderate-quality, and $2(11 \%)$ low-quality studies in the meta-analysis.

\section{Systematic Review}

The studies included in the systematic review were grouped according to how the tEMG was used. Table 2 summarizes all of the studies that provided relevant evidence on tEMG data, results, and outcomes.

\section{Lumbar PSs}

In total, data from 2594 patients who underwent lumbar spinal fixation were included in the systematic review. Postoperative neurological deficits were observed in only 8 patients $(0.3 \%)$. Triggered electromyography was first used in lumbar PS fixation by Calancie et al. ${ }^{4}$ Their study reported that without the use of tEMG, 12 of 21 screws that perforated the pedicle would have gone unnoticed by the surgeon. Alemo and Sayadipour ${ }^{1}$ reported that tEMG gave 3 false negatives (i.e., screws that were malpositioned according to postoperative CT scans but whose current was not below the tEMG threshold) that resulted in postoperative neurological deficits. Bindal and Ghosh ${ }^{2}$ performed a retrospective review of the data from 25 patients who underwent minimally invasive transforaminal lumbar interbody fusion. The authors reported that the trajectories of $80(76.2 \%)$ of 105 PSs were adjusted after detection of a tEMG signal. Postoperative CT scans revealed no medially or laterally misplaced screws, and no postoperative neurological deficits were observed in any of the patients.

\section{Thoracic PSs}

Of 433 patients who underwent placement of thoracic PSs with tEMG monitoring, none had any reported postoperative neurological deficits. In a study by Calancie et 
TABLE 1. Quality assessment with the Downs and Black checklist ${ }^{10}$ of the studies included in the systematic analysis of this study*

\begin{tabular}{|c|c|c|c|c|c|c|}
\hline Authors \& Year & $\begin{array}{l}\text { Reporting } \\
\text { Subscore }\end{array}$ & $\begin{array}{l}\text { External } \\
\text { Validity } \\
\text { Subscore }\end{array}$ & $\begin{array}{c}\text { Internal } \\
\text { Validity-Bias } \\
\text { Subscore }\end{array}$ & $\begin{array}{l}\text { Internal Validity- } \\
\text { Confounding } \\
\text { (selection bias) } \\
\text { Subscore }\end{array}$ & $\begin{array}{l}\text { Power } \\
\text { Subscore }\end{array}$ & $\begin{array}{c}\text { Quality Index } \\
\text { Score }\end{array}$ \\
\hline de Blas et al., 2012 & 11 & 1 & 6 & 4 & 0 & 22 \\
\hline Holdefer et al., 2013 & 9 & 1 & 7 & 5 & 0 & 22 \\
\hline Moed et al., 1998 & 9 & 3 & 6 & 4 & 0 & 22 \\
\hline Calancie et al., 2014 & 9 & 2 & 6 & 4 & 0 & 21 \\
\hline Parker et al., $2011^{25}$ & 9 & 3 & 5 & 4 & 0 & 21 \\
\hline Raynor et al., 2002 & 10 & 1 & 5 & 4 & 0 & 20 \\
\hline Donohue et al., 2008 & 9 & 2 & 4 & 4 & 0 & 19 \\
\hline Bindal \& Ghosh, 2007 & 10 & 1 & 5 & 3 & 0 & 19 \\
\hline Samdani et al., 2011 & 9 & 1 & 5 & 3 & 0 & 18 \\
\hline Regidor et al., 2011 & 7 & 1 & 6 & 4 & 0 & 18 \\
\hline Reidy et al., 2001 & 7 & 1 & 6 & 4 & 0 & 18 \\
\hline Maguire et al., 1995 & 8 & 1 & 4 & 4 & 0 & 17 \\
\hline Raynor et al., 2007 & 7 & 1 & 5 & 4 & 0 & 17 \\
\hline Wang et al., 2010 & 10 & 1 & 3 & 3 & 0 & 17 \\
\hline Silverstein \& Mermelstein, 2010 & 8 & 1 & 4 & 3 & 0 & 16 \\
\hline Djurasovic et al., 2005 & 5 & 1 & 6 & 4 & 0 & 16 \\
\hline Shi et al., 2003 & 6 & 1 & 6 & 3 & 0 & 16 \\
\hline Alemo \& Sayadipour, 2010 & 8 & 1 & 4 & 3 & 0 & 16 \\
\hline Rodriguez-Olaverri et al., 2008 & 6 & 1 & 5 & 3 & 1 & 16 \\
\hline Castellon et al., 2009 & 9 & 1 & 3 & 2 & 1 & 16 \\
\hline Welch et al., 1997 & 7 & 1 & 4 & 3 & 0 & 15 \\
\hline Toleikis et al., 2000 & 6 & 1 & 4 & 4 & 0 & 15 \\
\hline Glassman et al., 1995 & 5 & 1 & 6 & 3 & 0 & 15 \\
\hline Calancie et al., 1994 & 6 & 1 & 4 & 3 & 0 & 14 \\
\hline Lenke et al., 1995 & 5 & 1 & 4 & 4 & 0 & 14 \\
\hline Ozgur et al., 2006 & 4 & 1 & 3 & 3 & 0 & 11 \\
\hline Mean of all studies (SD) & $7.65(1.84)$ & $1.23(0.58)$ & $4.85(1.10)$ & $3.54(0.63)$ & $0.08(0.27)$ & $17.30(2.74)$ \\
\hline
\end{tabular}

al., ${ }^{3} 71$ patients underwent elective surgery that involved thoracic screws. Using CT scanning as a reference standard, the authors calculated an ROC curve with an AUC of 0.93 . Reidy et al. ${ }^{32}$ conducted a similar analysis in 17 patients and, using CT scanning as a reference standard, calculated an ROC AUC of 0.82 .

\section{Cervical Spine Fixation}

Two studies reported using tEMG in cervical spine fusion cases involving both lateral mass screws and PSs. Holdefer et al. ${ }^{15}$ examined screw placement outcomes in 2 groups of patients; in 1 group (the tEMG group), the surgeon was notified of tEMG results intraoperatively in real time, and in another (used as a control group), the surgeon was blinded to the intraoperative tEMG results. In the tEMG group, the rate of misplaced screws was $0 \%$, whereas the control group had a rate of $4.5 \%$. None of the 32 patients in the study showed postoperative neurological deficits.

\section{Iliosacral Screws}

Only one study reported using tEMG to guide placement of iliosacral screws. In the study by Moed et al., ${ }^{22}$ 27 patients underwent insertion of iliosacral screws for the treatment of unstable pelvic fractures. None of these patients displayed postoperative neurological deficits. No false positives were observed, indicating that the use of tEMG had a specificity of $100 \%$ in this study. Since no screw breaches were identified by postoperative CT scans, the authors could not calculate sensitivity. However, they reported that the drill bit was redirected 4 times overall, because of detection of a tEMG signal after a stimulating current below an 8-mA threshold had been applied.

\section{Meta-Analysis}

Of the 26 studies reviewed in this study, 18 (69\%) had the data required for inclusion in the meta-analysis; all of these studies investigated the use of tEMG for monitoring PS placement. Data from 2932 patients and from 15,065 


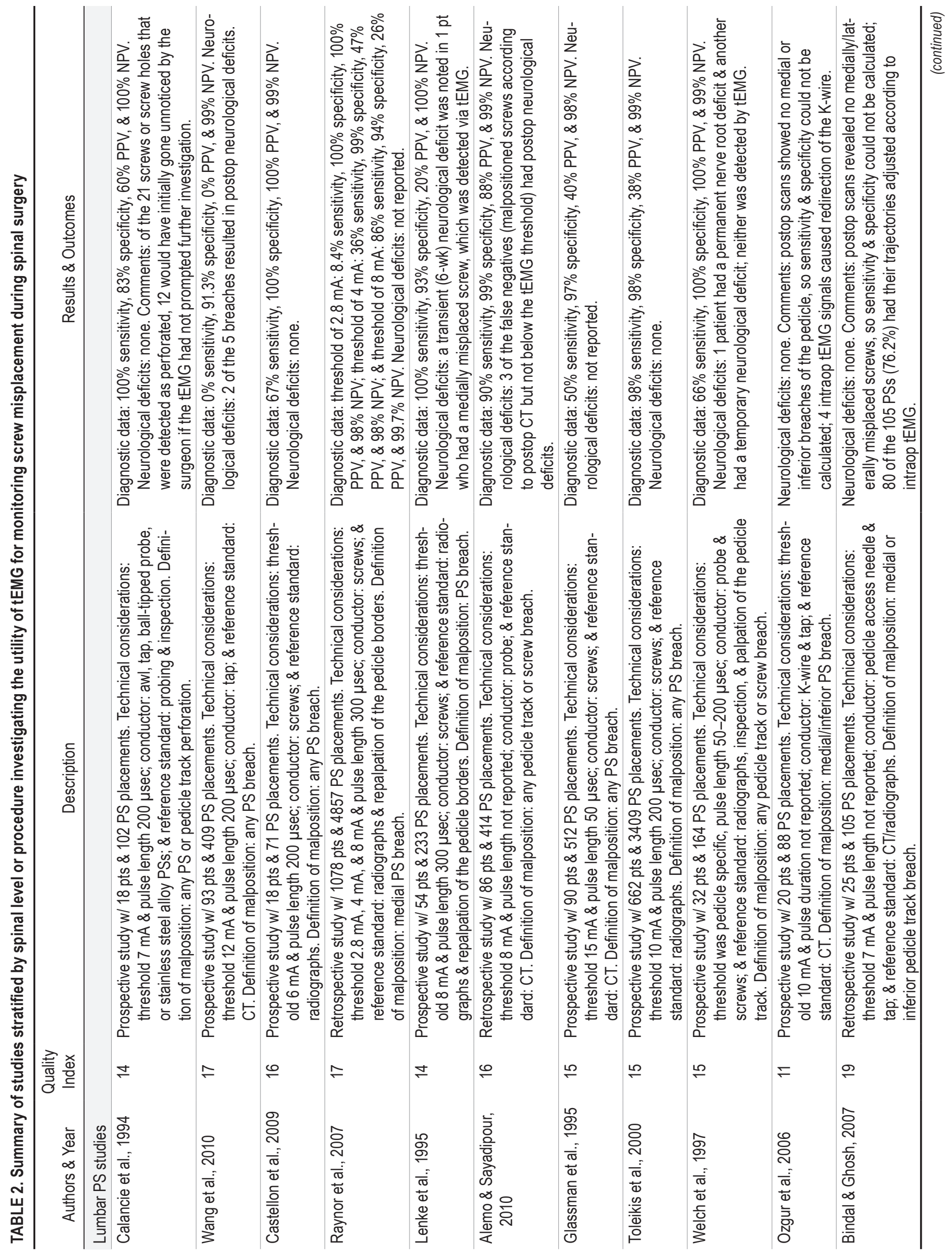




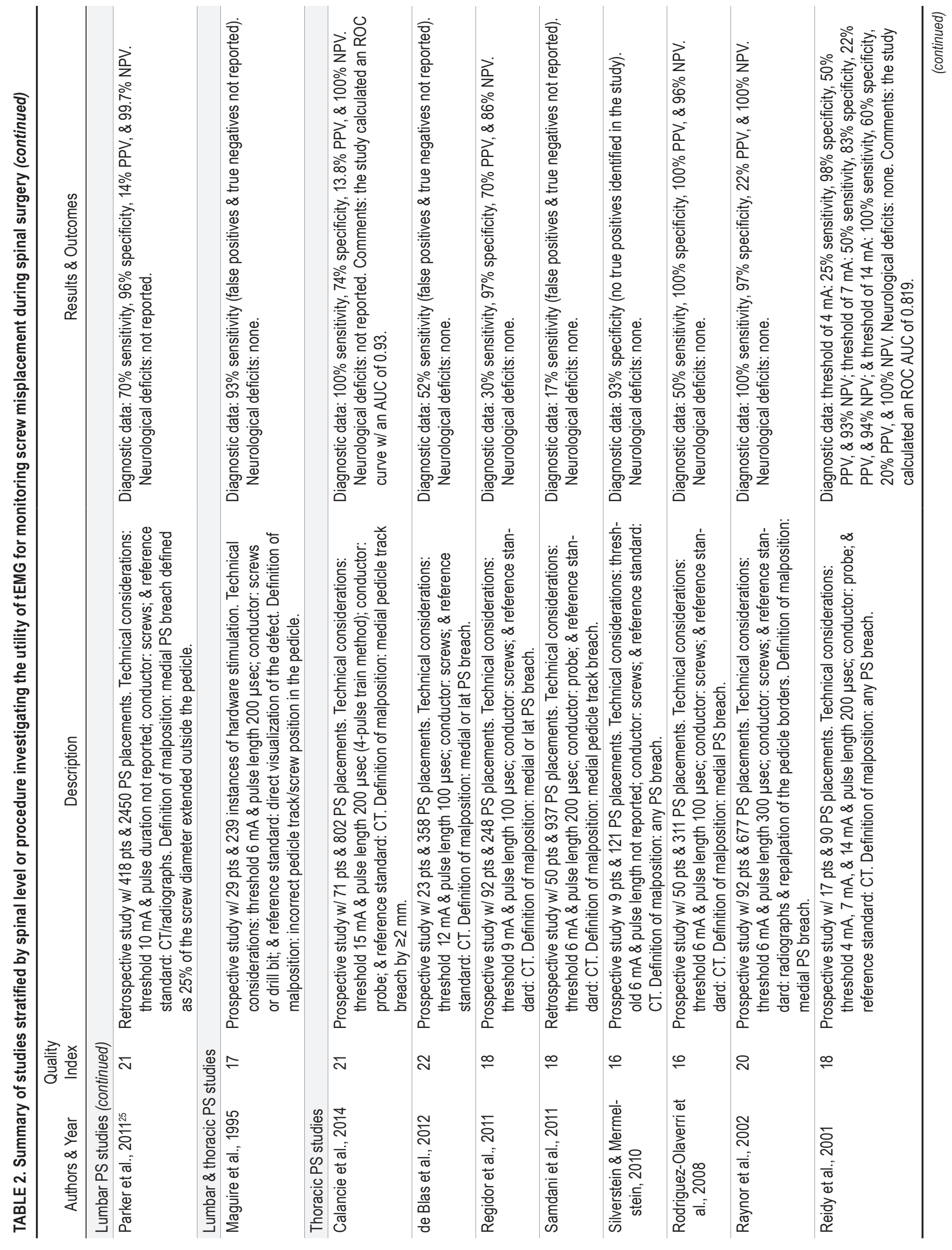




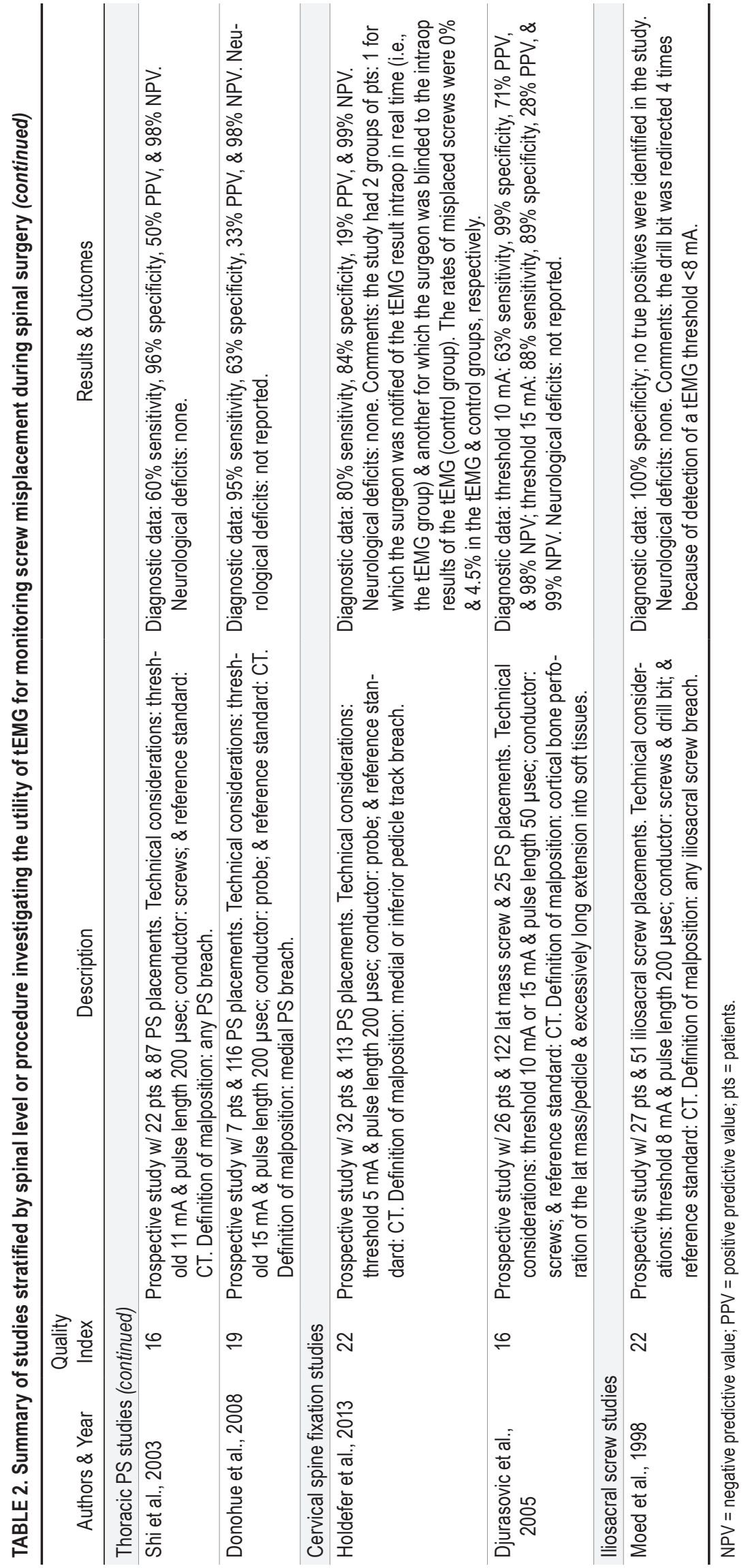


PSs were included in this meta-analysis. The data were analyzed on a per-screw basis.

\section{Threshold}

The overall sensitivity of tEMG (Fig. 2) for detecting misplaced PSs was 0.78 (95\% CI 0.73-0.82), and its specificity (Fig. 3) was 0.94 (95\% CI 0.94-0.95). The ROC AUC was 0.96 (Fig. 4), and both sensitivity and specificity of the studies included in the meta-analysis had high levels of heterogeneity with $\mathrm{I}^{2}$ values of $88.4 \%$ (Fig. 2) and $97.4 \%$ (Fig. 3), respectively.

The studies were stratified into 4 groups according to the electrical current threshold used in tEMG: 4-6 mA, 7-9 mA, 10-12 mA, and 14-15 mA (Table 3). Analysis of the ROC AUC was used to examine the diagnostic accuracy based on the current threshold. The AUC was generally large for all thresholds, ranging from 0.93 to 0.99 (Fig. 5). A current threshold of 10-12 mA gave the highest AUC (0.99) with a sensitivity of 0.82 and a specificity of 0.97 ; both sensitivity and specificity for this threshold were highly heterogeneous with $\mathrm{I}^{2}$ values of $91.3 \%$ and $92.0 \%$, respectively.

\section{Pulse Duration}

The studies analyzed here used tEMG pulse lengths ranging from 50 to $300 \mu \mathrm{sec}$ (Table 3). The ROC AUC was 0.97 for a pulse length of $300 \mu$ sec. This $300-\mu$ sec pulse duration had a detection sensitivity of 0.85 and a specificity of 0.95 . The sensitivity had moderate heterogeneity, and the specificity had high heterogeneity with $\mathrm{I}^{2}$ values of
$58.0 \%$ and $85.4 \%$, respectively. A pulse length of $200 \mu \mathrm{sec}$ had a lower AUC (0.95) but a higher sensitivity (0.90).

\section{Triggered EMG Conductors}

The surgeons in the studies analyzed used different instruments to conduct the tEMG current to tissues, including a probe, screw, tap, awl, or drill bit (Table 4). When the current was applied directly to the probe, the sensitivity of detection was 0.91 , specificity was 0.75 , and ROC AUC was 0.86 . When the current was applied to the screws, sensitivity decreased to 0.73 , specificity increased to 0.96 , and the AUC was 0.98. Thus, current conduction through the probe gave a higher sensitivity and a lower specificity than that through the screws.

Some studies used a combination of both probe and screw stimulation. The sensitivity in this subgroup was 0.86 , specificity was 0.94 , and the AUC was 0.97 . Screw stimulation alone had a higher AUC, which indicated that screws were the more accurate diagnostic conductor.

\section{Anatomical Region of the Spine}

Two studies that had analyzed PS placement in the cervical spine were available in the meta-analysis, and only one of these studies analyzed purely cervical PSs. Therefore, a cervical spine subgroup was not included in the meta-analysis.

Overall, the sensitivity of PS placement in the lumbar region was 0.84 (95\% CI $0.80-0.88)$, the specificity in this region was 0.96 (95\% CI 0.95-0.96), and the ROC AUC was 0.98 (Table 5). When we analyzed the data for

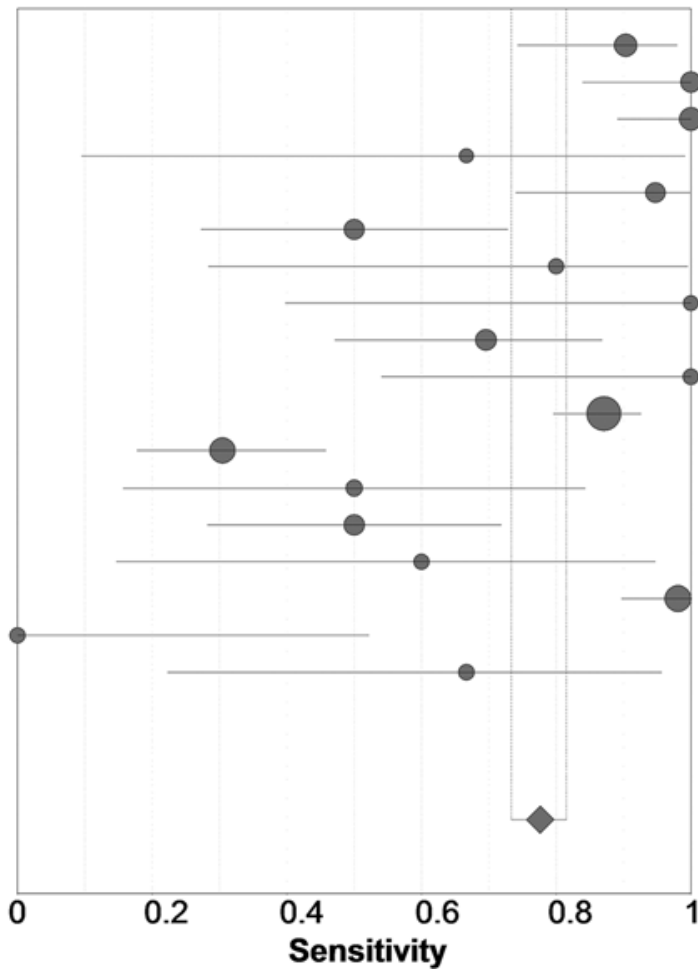

Alemo et al. (2010)

Calancie et al. (1994)

Calancie et al. (2014)

Castellon et al. (2009)

Donohue et al. (2008)

Glassman et al. (1995)

Holdefer et al. (2013)

Lenke et al. (1995)

Parker et al. (2011) 25

Raynor et al. (2002)

Raynor et al. (2007)

Regidor et al. (2011)

Reidy et al. (2001)

Rodriguez-Olaverri et al.

Shi et al. (2003)

Toleikis et al. (2000)

Wang et al. (2010)

Welch et al. (1997)

\section{Sensitivity $(95 \% \mathrm{Cl})$}

$\begin{array}{ll}0.90 & (0.74-0.98) \\ 1.00 & (0.84-1.00) \\ 1.00 & (0.89-1.00) \\ 0.67 & (0.09-0.99) \\ 0.95 & (0.74-1.00) \\ 0.50 & (0.27-0.73) \\ 0.80 & (0.28-0.99) \\ 1.00 & (0.40-1.00) \\ 0.70 & (0.47-0.87) \\ 1.00 & (0.54-1.00) \\ 0.87 & (0.80-0.93) \\ 0.30 & (0.18-0.46) \\ 0.50 & (0.16-0.84) \\ 0.50 & (0.28-0.72) \\ 0.60 & (0.15-0.95) \\ 0.98 & (0.90-1.00) \\ 0.00 & (0.00-0.52) \\ 0.67 & (0.22-0.96)\end{array}$

Pooled Sensitivity $=0.78$ (0.73 to 0.81$)$

Heterogeneity (I-square) $=88.4 \%$

FIG. 2. Forest plot indicating overall sensitivity for all PS studies included in the meta-analysis. Circle sizes correspond to study sizes, and horizontal lines for each study indicate the $95 \% \mathrm{Cl}$. The diamond indicates pooled sensitivity. 


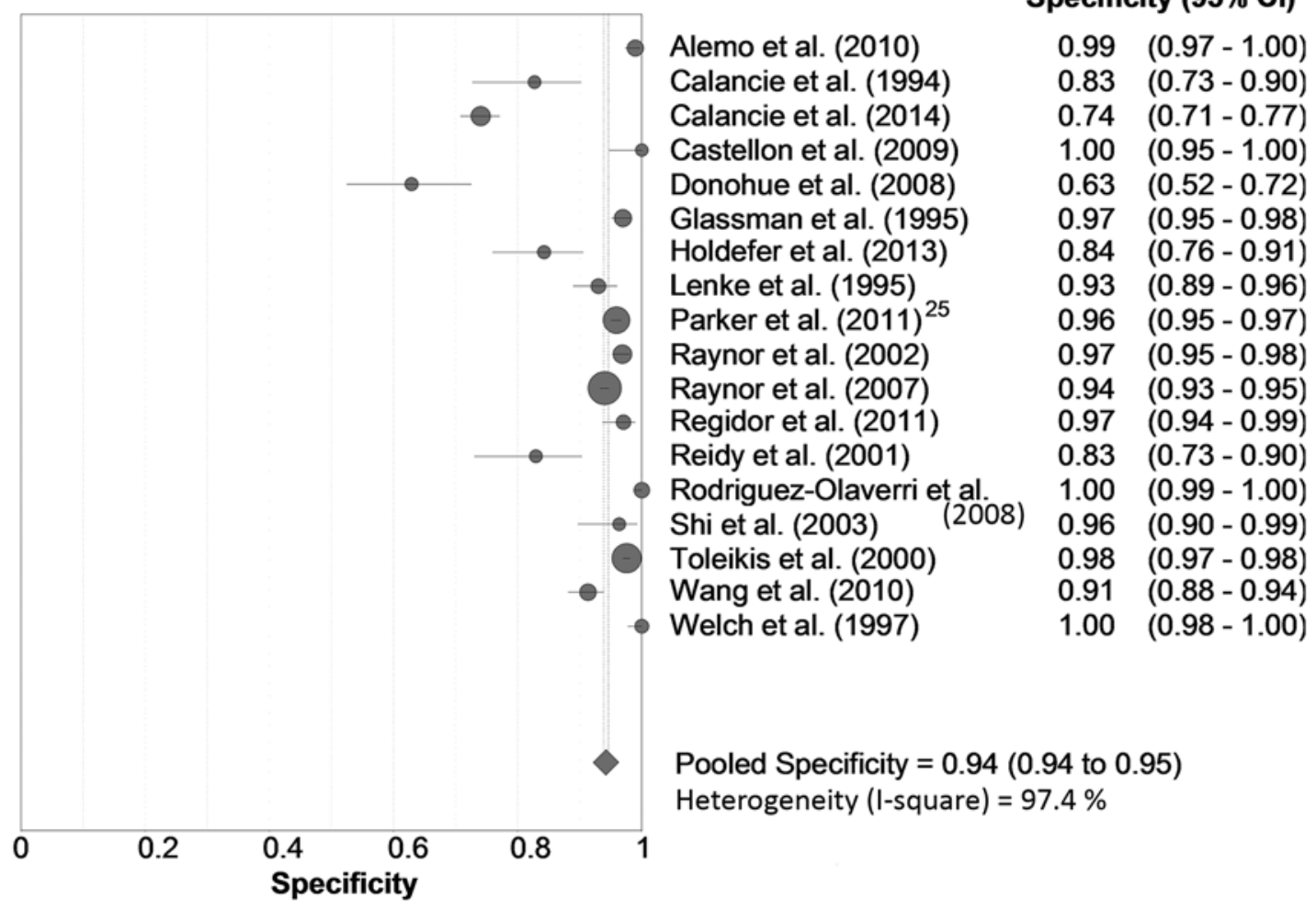

Specificity $(95 \% \mathrm{Cl})$

$0.99 \quad(0.97-1.00)$

$0.83 \quad(0.73-0.90)$

(0.71- 0.77$)$

$0.97 \quad(0.95-0.98)$

$0.84 \quad(0.76-0.91)$

$0.93 \quad(0.89-0.96)$

$0.96 \quad(0.95-0.97)$

$0.97 \quad(0.95-0.98)$

(0.93-0.95)

$1.00 \quad(0.99-1.00)$

$0.96 \quad(0.90-0.99)$

$0.98 \quad(0.97-0.98)$

$0.88-0.94)$

$(0.98-1.00)$

FIG. 3. Forest plot indicating overall specificity for all PS studies included in the meta-analysis. Circle sizes correspond to study sizes, and horizontal lines for each study indicate the $95 \% \mathrm{Cl}$. The diamond indicates pooled specificity.

the current-threshold subgroups of the lumbar PS placements, a threshold of $10-15 \mathrm{~mA}$ had the highest ROC AUC (0.995) and thus provided most accurate testing for PS misplacement. The overall sensitivity of tEMG for detecting PS misplacement in the thoracic region was 0.64 (95\% CI 0.55-0.72), and its specificity in this region was

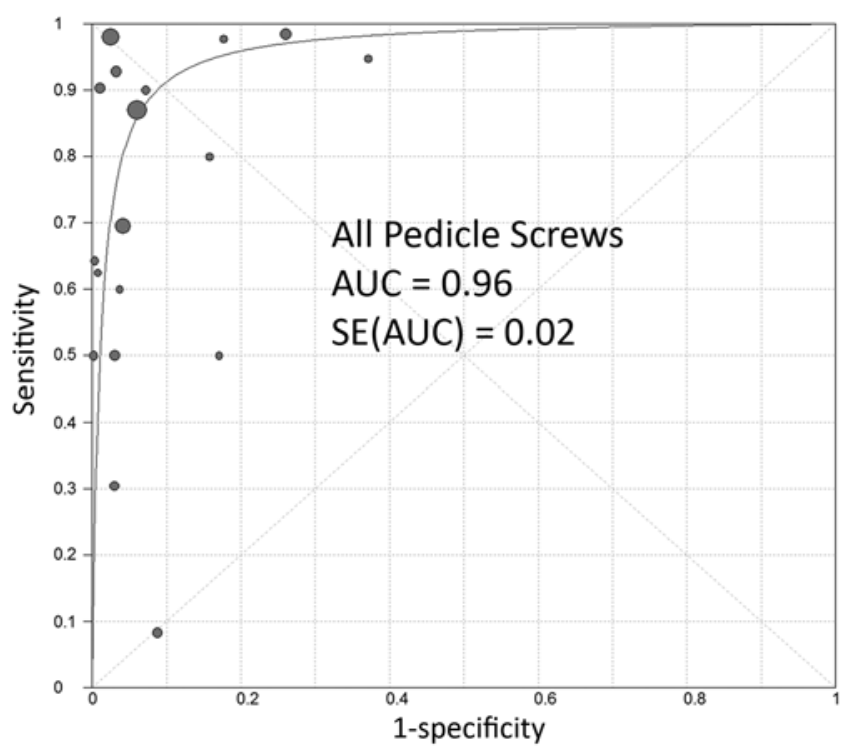

FIG. 4. ROC curve representing all PS studies included in the metaanalysis. $\mathrm{SE}(\mathrm{AUC})=$ standard error of the $\mathrm{AUC}$.
0.87 (95\% CI 0.86-0.89), both of which were lower than those in the lumbar region; the ROC AUC was 0.93. When we analyzed current-threshold subgroups for thoracic PSs, a threshold of 6-11 mA had the highest AUC (0.88) and thus provided most accurate testing for PS misplacement (Table 5).

\section{Thoracic Probe Versus Screw}

We also compared the accuracy of tEMG conductors at the thoracic level (Table 5). Screw stimulation gave a higher ROC AUC (0.96) than probe stimulation (0.85). However, probe stimulation gave much higher sensitivity (0.92) than screw stimulation (0.43).

\section{Reference Standard and Definition of Malposition}

To determine screw malposition, the studies used different reference standards, including CT, radiographs, probing, and direct visualization. When controlling for these differences, we found a difference of less than $10 \%$ in ROC AUC or specificity. However, studies using CT as a reference standard had a lower sensitivity (0.64) than studies that used radiographs (0.96) or probing or visualization (0.90).

The studies included also defined screw malposition differently. Some defined it as any screw or track breach in the pedicle, whereas others specified that the screw or track had to perforate the pedicle medially for it to be determined as misplaced. When we controlled for these differences among studies, we observed a change of more than $10 \%$ in sensitivity, specificity, or ROC AUC. 
TABLE 3. Results of the meta-analysis with studies subgrouped by stimulating current threshold and pulse length

\begin{tabular}{|c|c|c|c|c|c|c|c|}
\hline \multirow{2}{*}{$\begin{array}{c}\text { Threshold/Pulse } \\
\text { Length }\end{array}$} & \multirow{2}{*}{$\begin{array}{l}\text { No. of } \\
\text { Studies }\end{array}$} & \multirow{2}{*}{$\begin{array}{l}\text { No. of } \\
\text { Screws }\end{array}$} & \multicolumn{2}{|c|}{ Sensitivity } & \multicolumn{2}{|l|}{ Specificity } & \multirow[b]{2}{*}{ ROC AUC (SE) } \\
\hline & & & Value $(95 \% \mathrm{Cl})$ & $\mathrm{I}^{2}(\%)$ & Value $(95 \% \mathrm{Cl})$ & $\mathrm{I}^{2}(\%)$ & \\
\hline \multicolumn{8}{|l|}{ Threshold (mA) } \\
\hline $4-6$ & 6 & 6119 & $0.42(0.34-0.50)$ & 71.2 & $0.99(0.98-0.99)$ & 93.8 & $0.93(0.05)$ \\
\hline $7-9$ & 6 & 5944 & $0.76(0.70-0.82)$ & 93.0 & $0.94(0.93-0.95)$ & 90.7 & $0.96(0.03)$ \\
\hline $10-12$ & 4 & 6355 & $0.82(0.73-0.90)$ & 91.3 & $0.97(0.96-0.97)$ & 92.0 & $0.99(0.00)$ \\
\hline $14-15$ & 4 & 1520 & $0.86(0.77-0.93)$ & 89.4 & $0.80(0.78-0.82)$ & 98.3 & $0.93(0.02)$ \\
\hline \multicolumn{8}{|l|}{ Pulse length ( $\mu s e c)$} \\
\hline $50-100$ & 3 & 1071 & $0.40(0.30-0.51)$ & 43.3 & $0.98(0.97-0.99)$ & 86.5 & $0.37(0.57)$ \\
\hline 200 & 9 & 5199 & $0.90(0.84-0.94)$ & 85.0 & $0.92(0.91-0.93)$ & 98.4 & $0.95(0.03)$ \\
\hline 300 & 4 & 8217 & $0.85(0.79-0.91)$ & 58.0 & $0.95(0.94-0.95)$ & 85.4 & $0.97(0.01)$ \\
\hline All studies & 18 & 15,065 & $0.78(0.73-0.82)$ & 88.4 & $0.94(0.94-0.95)$ & 97.4 & $0.96(0.02)$ \\
\hline
\end{tabular}

$\mathrm{SE}=$ standard error.

\section{Sensitivity Analysis}

We performed a sensitivity analysis by single elimination of each study from the overall results and in subgroups according to current threshold, pulse duration, and conductors. The sensitivity analysis of the overall results indicated no appreciable change, defined as a change of $10 \%$ or greater, in the observed outcomes (Table 6).
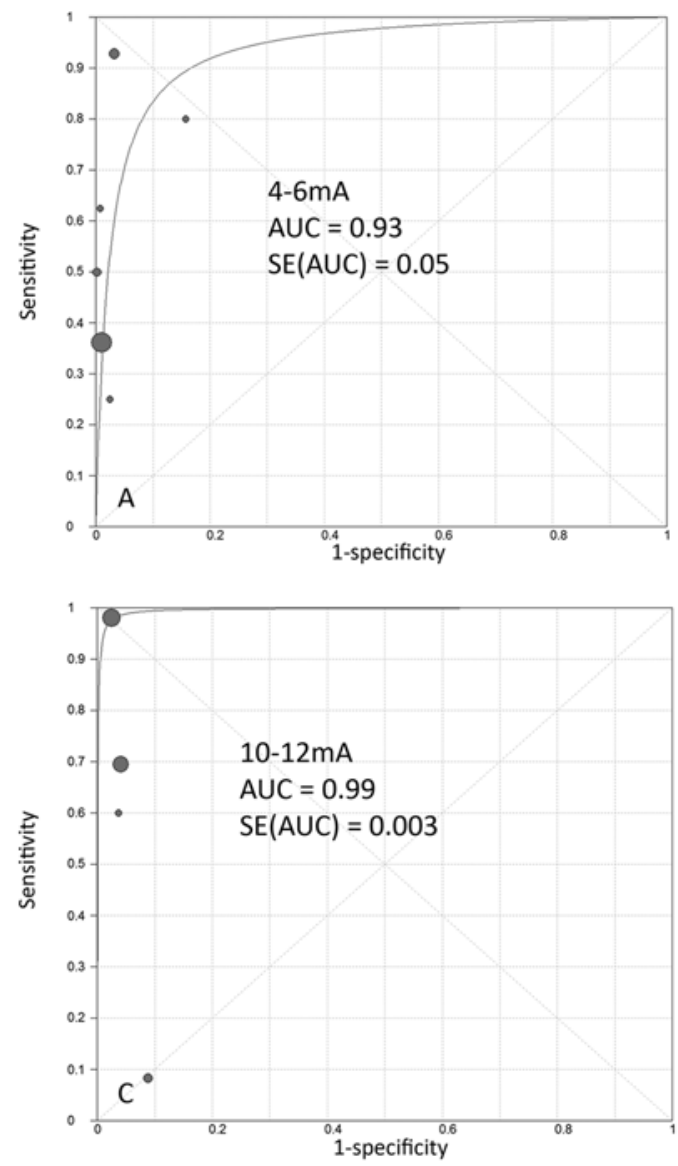

Among the current-threshold subgroups, removing 5 studies from the analysis produced an appreciable change in sensitivity. ${ }^{3,12,29,31,38}$ When the study by Glassman et al. ${ }^{12}$ was removed from the subgroup analysis, it produced appreciable changes in sensitivity, specificity, and ROC AUC. Within the pulse-duration subgroups, eliminating Regidor et al. ${ }^{31}$ produced an appreciable change in sensitivity, and
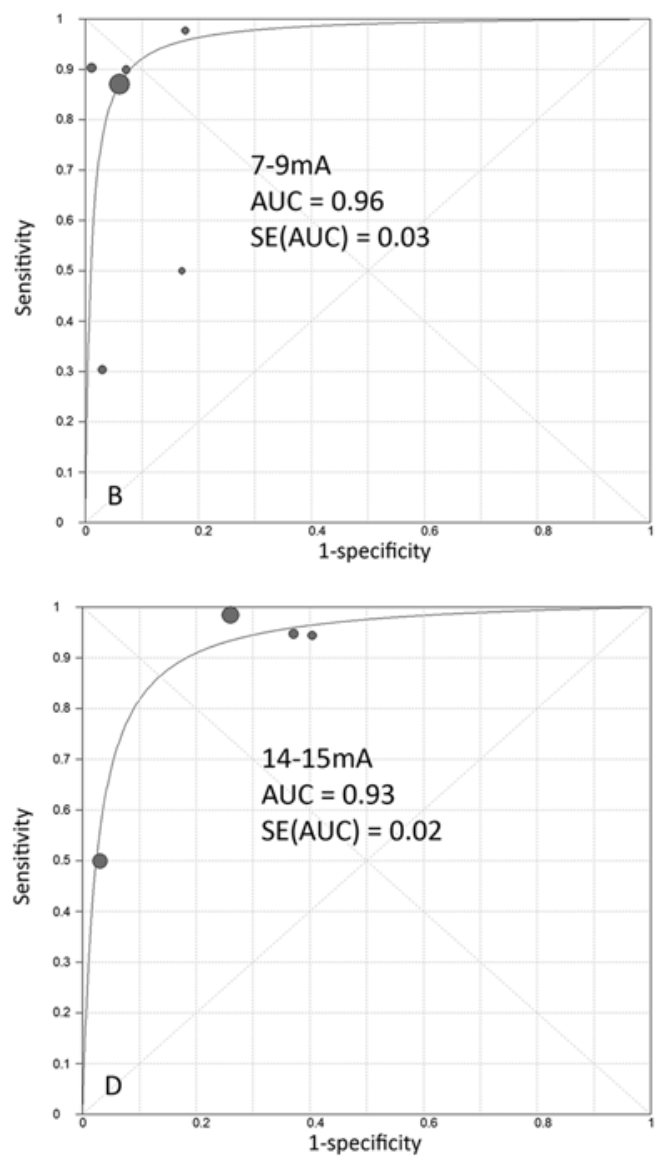

FIG. 5. ROC curves representing PS studies grouped by threshold of the stimulating electrical current. Panels A, B, C, and D represent PS studies grouped by thresholds of 4-6 mA, 7-9 mA, 10-12 mA, and 14-15 mA, respectively. Circle sizes correspond to study sizes. 
TABLE 4. Results of the meta-analysis with studies subgrouped by current conductor type

\begin{tabular}{|c|c|c|c|c|c|c|c|}
\hline \multirow[b]{2}{*}{ Threshold (mA) } & \multirow{2}{*}{$\begin{array}{l}\text { No. of } \\
\text { Studies }\end{array}$} & \multirow{2}{*}{$\begin{array}{l}\text { No. of } \\
\text { Screws }\end{array}$} & \multicolumn{2}{|l|}{ Sensitivity } & \multicolumn{2}{|l|}{ Specificity } & \multirow{2}{*}{$\begin{array}{l}\text { ROC AUC } \\
\text { (SEM) }\end{array}$} \\
\hline & & & Value $(95 \% \mathrm{Cl})$ & $\mathrm{I}^{2}(\%)$ & Value $(95 \% \mathrm{Cl})$ & $\mathrm{I}^{2}(\%)$ & \\
\hline \multicolumn{8}{|l|}{ Probe } \\
\hline $5-15$ & 4 & 1121 & $0.91(0.81-0.97)$ & 81.1 & $0.75(0.72-0.77)$ & 80.9 & $0.86(0.04)$ \\
\hline \multicolumn{8}{|l|}{ Screw } \\
\hline $4-6$ & 4 & 5916 & $0.42(0.33-0.50)$ & 77.5 & $0.99(0.99-0.99)$ & 88.0 & $0.98(0.02)$ \\
\hline $8-9$ & 3 & 5338 & $0.72(0.64-0.78)$ & 96.2 & $0.94(0.93-0.95)$ & 53.6 & $0.98(0.01)$ \\
\hline $10-15$ & 4 & 6458 & $0.80(0.71-0.87)$ & 89.1 & $0.97(0.96-0.97)$ & 75.7 & $0.99(0.00)$ \\
\hline All studies & 10 & 12,855 & $0.73(0.68-0.78)$ & 90.1 & $0.96(0.95-0.96)$ & 91.3 & $0.98(0.01)$ \\
\hline \multicolumn{8}{|c|}{$\begin{array}{l}\text { Combination probe, screw, tap, } \\
\text { awl, \& drill bit }\end{array}$} \\
\hline $7-12$ & 3 & 925 & $0.86(0.74-0.94)$ & 92.5 & $0.94(0.92-0.95)$ & 95.2 & $0.97(0.05)$ \\
\hline
\end{tabular}

$\mathrm{SEM}=$ standard error of the mean.

removing Toleikis et al. ${ }^{38}$ produced an appreciable change in specificity. Among the conductor subgroups, eliminating 3 studies produced an appreciable change in sensitivity. ${ }^{3,29,31}$

\section{Publication Bias}

Publication bias was evaluated via 1-tailed funnel plots for analysis of both sensitivity and specificity (Figs. 6 and 7). The sensitivity analysis indicated 1 outlier (i.e., Wang et al. ${ }^{41}$; Fig. 6), which had a low sensitivity and a small number of screws and therefore a high standard error. The specificity analysis gave more consistent results, with standard errors of the studies being lower than those for sensitivity.

\section{Discussion}

The purpose of this study was to assess the reliability of intraoperative tEMG for detecting misplaced PSs in real time. By comparing muscle action potentials of innervated myotomes to those at adjacent levels or of a known standard, a surgeon is theoretically able to monitor the prox- imity of the surgical instrumentation to neural structures. The results of this meta-analysis indicated that tEMG detects misplaced screws with high specificity but with only fair sensitivity (up to $22 \%$ of misplaced screws could be missed by tEMG). The accuracy of this method varied by current threshold, pulse duration, conductor used, and anatomical area. A current threshold of 10-12 mA provided the most accurate test according to the ROC AUC analysis. A pulse length of $300 \mu \mathrm{sec}$ gave the most accurate detection, although a pulse duration of $200 \mu \mathrm{sec}$ had the highest sensitivity. Current conduction via the screw gave the most accurate detection according to the ROC AUC analysis, but probe conduction gave the highest sensitivity. One limitation when using the probe as the conduction device is that during its stimulation it may be located entirely in the pedicle; we note that the screw has a larger diameter, and when it is inserted into the pedicle, it may penetrate the cortex.

The relatively low overall sensitivity of tEMG observed across the studies analyzed indicates that up to $22 \%$ of misplaced screws may not be detected by tEMG. Use of tEMG may give the surgeon a false sense of security and

TABLE 5. Results of the meta-analysis of tEMG sensitivity and specificity in screw placement stratified by thoracic and lumbar segments

\begin{tabular}{|c|c|c|c|c|c|c|c|}
\hline \multirow[b]{2}{*}{ Threshold (mA) } & \multirow[b]{2}{*}{ No. of Studies } & \multirow[b]{2}{*}{ No. of Screws } & \multicolumn{2}{|l|}{ Sensitivity } & \multicolumn{2}{|l|}{ Specificity } & \multirow[b]{2}{*}{ ROC AUC (SE) } \\
\hline & & & Value (95\% Cl) & $\mathrm{I}^{2}(\%)$ & Value (95\% Cl) & $1^{2}(\%)$ & \\
\hline \multicolumn{8}{|l|}{ All lumbar screws } \\
\hline $4-7$ & 3 & 5030 & $0.46(0.38-0.55)$ & 94.7 & $0.99(0.98-0.99)$ & 96.3 & $0.97(0.02)$ \\
\hline 8 & 3 & 5504 & $0.88(0.82-0.93)$ & 0.0 & $0.94(0.94-0.95)$ & 91.8 & $0.92(0.03)$ \\
\hline $10-15$ & 4 & 6780 & $0.77(0.68-0.85)$ & 92.9 & $0.97(0.96-0.97)$ & 92.1 & $0.995(0.00)$ \\
\hline All studies & 10 & 12,621 & $0.84(0.80-0.88)$ & 84.3 & $0.96(0.95-0.96)$ & 93.4 & $0.98(0.01)$ \\
\hline \multicolumn{8}{|l|}{ All thoracic screws } \\
\hline $6-11$ & 5 & 1413 & $0.44(0.33-0.55)$ & 72.1 & $0.97(0.96-0.98)$ & 91.0 & $0.88(0.15)$ \\
\hline $14-15$ & 3 & 1008 & $0.98(0.91-1.0)$ & 13.1 & $0.72(0.69-0.75)$ & 81.8 & $0.15(0.53)$ \\
\hline All studies & 7 & 2331 & $0.64(0.55-0.72)$ & 91.2 & $0.87(0.86-0.89)$ & 98.1 & $0.93(0.04)$ \\
\hline \multicolumn{8}{|c|}{ Thoracic level probe conduction } \\
\hline $7-15$ & 3 & 1008 & $0.92(0.81-0.97)$ & 86.9 & $0.74(0.71-0.76)$ & 78.8 & $0.85(0.05)$ \\
\hline \multicolumn{8}{|c|}{ Thoracic level screw conduction } \\
\hline $6-11$ & 4 & 1323 & $0.43(0.32-0.55)$ & 78.9 & $0.98(0.97-0.98)$ & 81.5 & $0.96(0.08)$ \\
\hline
\end{tabular}


TABLE 6. Results of the sensitivity analysis

\begin{tabular}{|c|c|c|}
\hline Study Removed & Removed From Subgroup & Observed Effect \\
\hline Raynor et al., 2007 & 4- to 6-mA threshold & Sensitivity increased from 0.42 to $0.57(36.0 \%)$ \\
\hline Raynor et al., 2007 & 7- to 9-mA threshold & Sensitivity decreased from 0.76 to 0.65 (14.5\%) \\
\hline Regidor et al., 2011 & 7- to 9-mA threshold & Sensitivity increased from 0.76 to $0.88(15.8 \%)$ \\
\hline Toleikis et al., 2000 & 10- to $12-\mathrm{mA}$ threshold & Sensitivity decreased from 0.82 to $0.58(29.3 \%)$ \\
\hline Calancie et al., 2014 & 14- to 15-mA threshold & Sensitivity decreased from 0.86 to $0.77(10.5 \%)$ \\
\hline Glassman et al., 1995 & 14- to $15-\mathrm{mA}$ threshold & $\begin{array}{l}\text { Sensitivity increased from } 0.86 \text { to } 0.98(14.0 \%) \text {, specificity decreased from } 0.8 \text { to } 0.72 \\
(10.0 \%) \text {, \& ROC AUC decreased from } 0.93 \text { to } 0.15(83.9 \%)\end{array}$ \\
\hline Regidor et al., 2011 & $50-$ to $100-\mu$ sec pulse length & Sensitivity increased from 0.4 to $0.5(25.0 \%)$ \\
\hline Toleikis et al., 2000 & $200-\mu s e c$ pulse length & Specificity decreased from 0.92 to $0.81(12.0 \%)$ \\
\hline Calancie et al., 2014 & Probe conduction & Sensitivity decreased from 0.91 to $0.81(11.0 \%)$ \\
\hline Raynor et al., 2007 & Screw conduction & Sensitivity decreased from 0.73 to $0.65(11.0 \%)$ \\
\hline Regidor et al., 2011 & Screw conduction & Sensitivity increased from 0.73 to $0.81(11.0 \%)$ \\
\hline
\end{tabular}

could therefore result in harm to a patient. The surgeon, when using this technology in screw placement, must understand this limitation and should verify accurate screw placement by other means such as palpation, direct inspection when pedicles are exposed after decompression, and radiographic imaging. The specificity was high, meaning that a tEMG at low current thresholds indicates misplaced screws and requires careful assessment and screw repositioning as needed.

The tEMG current threshold for most reliable detection of screw misplacement varied by anatomical region. For lumbar procedures, a threshold of $10-15 \mathrm{~mA}$ provided the most accurate detection, and for thoracic procedures, 6-11 $\mathrm{mA}$ provided the most accurate detection. However, a current threshold of $14-15 \mathrm{~mA}$ provided the greatest sensitivity at the thoracic level.

The main goal of using tEMG during spinal surgery is to avoid neurological injury. The best way to determine the efficacy of tEMG for achieving this goal is a randomized controlled trial with the primary outcome being the presence or absence of a neurological injury. However, it is unethical to conduct a study in which tEMG warnings are not addressed and in which surgical actions are continued to assess the neurological outcomes of not responding to a warning. Therefore, it is challenging to determine whether a tEMG signal is a true or false positive. Researchers have tried to address this question in different ways. Some authors do not categorize individual tEMG signals as true or false positives, but instead cite improved postoperative neurological outcomes as support for the technology. 2,24,37 Others report how neurological structures were preserved through the use of tEMG, presumably preventing a neurological deficit. ${ }^{17,27}$ Some studies of PS placement have correlated tEMG thresholds with accurate PS placement. However, this approach does not directly measure the reliability of tEMG to prevent neurological injury because not all misplaced screws create neurological damage.,31

One concern regarding the use of this technique is that chronically compressed nerve roots may not respond to tEMG in the same way as healthy nerve roots do. Two studies not included in this systematic review analyzed data from injured nerve roots during decompression sur-

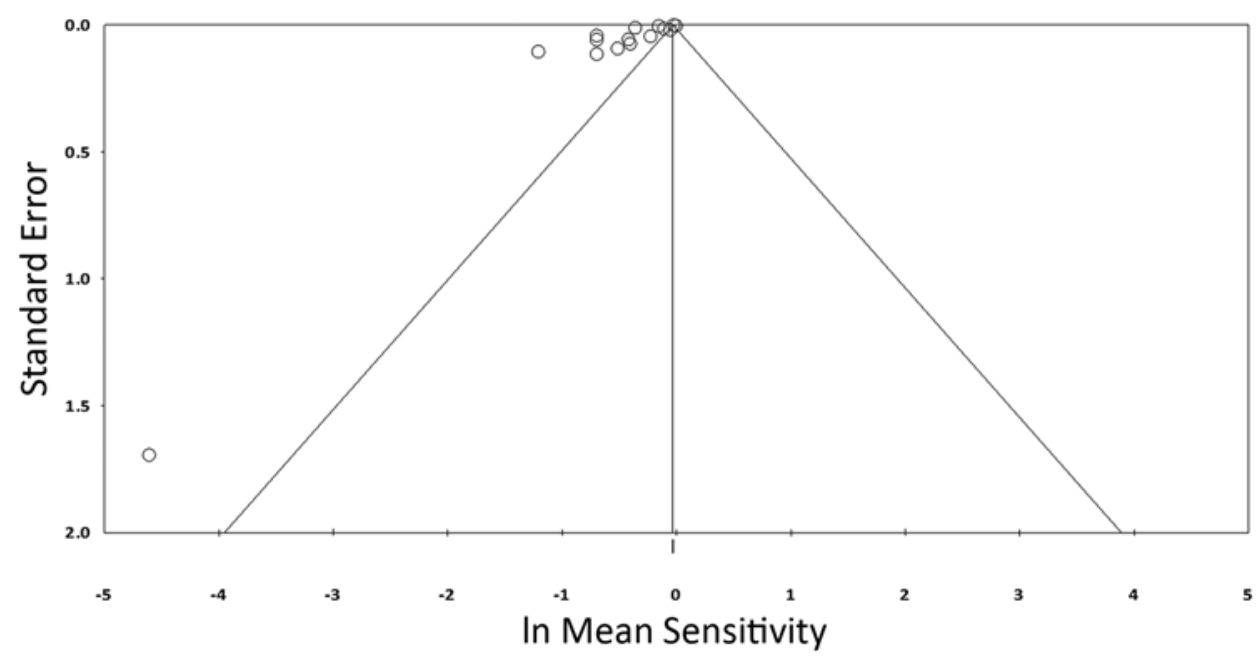

FIG. 6. Funnel plot of the sensitivity analysis to evaluate publication bias. The one outlier in the lower left quadrant of the graph corresponds to the study by Wang et al., which had a low sensitivity and a small number of screws and therefore a high standard error. In = natural logarithm. 


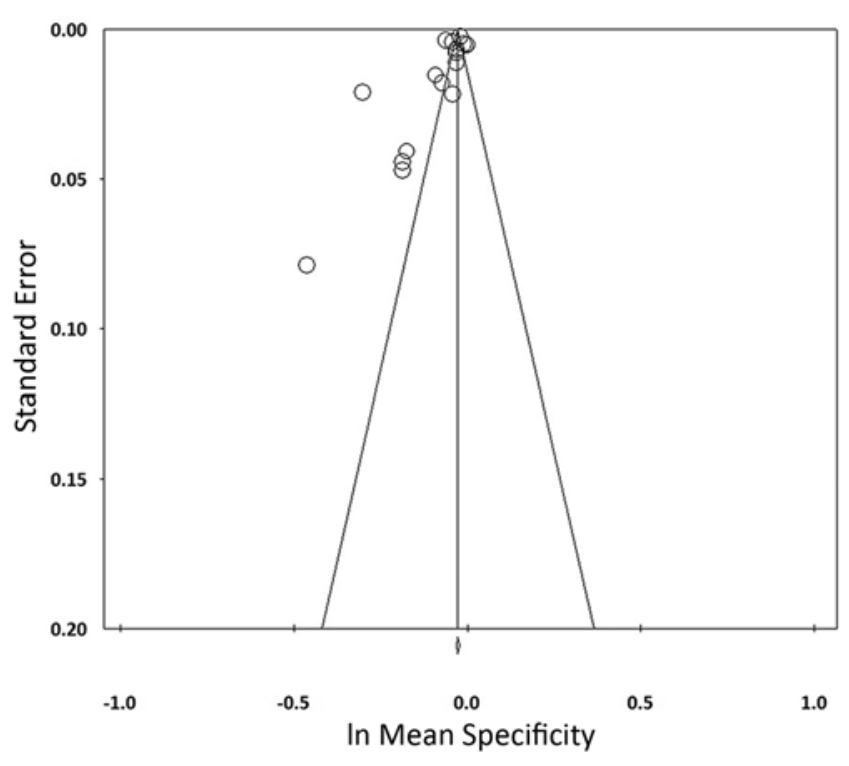

FIG. 7. Funnel plot of the specificity analysis to evaluate publication bias. In = natural logarithm.

gery. ${ }^{16,19}$ Both studies observed that injured or compressed nerve roots have significantly higher current thresholds than the control or decompressed nerves. This effect of nerve root injury may account for some of the heterogeneity observed in the accuracy of tEMG for detecting misplaced screws. This limitation of tEMG in the presence of chronically injured nerve roots needs to be recognized and may be addressed by increasing the current threshold to avoid further damaging these neural structures.

Calancie et al. ${ }^{3}$ demonstrated that at the thoracic level, electrical stimulation via a probe is more effective than screw stimulation to detect medially misplaced screws. We conducted a similar comparison using data from 7 studies, although not all of these studies had focused on the ability of tEMG to detect medially misplaced screws. Three of the studies defined lateral, superior, and inferior pedicle perforations as screw misplacement in addition to medial misplacement. We conclude that, at the thoracic level, electrical stimulation of the screw gives a higher ROC AUC (0.96) than stimulation of the probe $(0.85)$, reflecting a higher accuracy of the former stimulation type. However, we also observed that the stimulation via the probe gives a much higher sensitivity (0.92) than via the screw (0.43).

Surgeons concerned about false negatives may want to stimulate the probe during operations at the thoracic level, although they should be wary of the aforementioned potential limitation of probe stimulation. Furthermore, tEMG of PSs probably works best for detecting medial and foraminal screw malpositions affecting traversing and exiting nerve roots and is unlikely to detect anterior or lateral screw malposition. Whether tEMG can detect spinal cord injury due to misplaced screws is also unknown.

Triggered electromyography also is used for surgical applications other than PS placement. Minimally invasive techniques are being developed that lack direct visualization of the neural structures, which, in some cases, makes neuromonitoring essential to maintain patient safety. The primary example for this monitoring requirement is the lateral transpsoas approach for interbody fusion, which uses tEMG for probe and retractor placement and is gaining popularity in the management of spinal degenerative disorders. ${ }^{6}$ In addition, tEMG has been used to assess adequacy of foraminotomies and laminectomies, ${ }^{16}$ as an adjunct to lumbar microendoscopic discectomy, ${ }^{19}$ and during tethered spinal cord release. ${ }^{17,27,28,40}$ Therefore, systematic reviews and meta-analyses of the utility of tEMG for ensuring the safety of these procedures should be conducted.

The limitations of this study include the heterogeneity of the studies in the meta-analysis. The likely factors in causing this heterogeneity were study design, technical aspects of tEMG utilization, and the outcomes measured. We subgrouped the studies to account for some of these variables. The sensitivity analysis showed that no single study, when removed from the overall meta-analysis, produced an appreciable (i.e., $\geq 10 \%$ ) change in sensitivity, specificity, or ROC AUC. However, removal of 8 studies from the subgroup analysis produced an appreciable change in sensitivity, specificity, or AUC. Furthermore, the data sources used for this investigation varied considerably. Five of the studies were retrospective, ${ }^{1,2,25,29,34}$ which means bias could have been present in selecting patients for the study and recall bias may have occurred in studies in which additional patient follow-up had to be conducted. The prospective studies included in this review ${ }^{3-5,7}$ also had limitations, including loss to follow-up. Three of the PS studies did not include false positives and true negatives in their data, so they could not be included in the meta-analysis. ${ }^{7,20,34}$ Additionally, one study could not be included in the meta-analysis because it did not identify any misplaced screws. ${ }^{36}$

\section{Conclusions}

To our knowledge, this is the first study that has used a meta-analysis to quantify the utility of tEMG in detecting misplaced PSs. These results show how to best use tEMG while placing PSs. Although the technology has a high specificity, its fair sensitivity needs to be considered when tEMG is used during surgery. The results therefore highlight the limitations of this technology, most notably, its low sensitivity.

\section{Acknowledgments}

We acknowledge the support of the literature search by Christopher Hooper-Lane, MA, senior clinical medical librarian.

\section{References}

1. Alemo S, Sayadipour A: Role of intraoperative neurophysiologic monitoring in lumbosacral spine fusion and instrumentation: a retrospective study. World Neurosurg 73:72-76, e77, 2010

2. Bindal RK, Ghosh S: Intraoperative electromyography monitoring in minimally invasive transforaminal lumbar interbody fusion. J Neurosurg Spine 6:126-132, 2007

3. Calancie B, Donohue ML, Harris CB, Canute GW, Singla A, Wilcoxen KG, et al: Neuromonitoring with pulse-train stimulation for implantation of thoracic pedicle screws: a blinded and randomized clinical study. Part 1. Methods and alarm criteria. J Neurosurg Spine 20:675-691, 2014

4. Calancie B, Madsen P, Lebwohl N: Stimulus-evoked EMG 
monitoring during transpedicular lumbosacral spine instrumentation. Initial clinical results. Spine (Phila Pa 1976) 19:2780-2786, 1994

5. Castellon AT, Meves R, Avanzi O: Intraoperative neurophysiologic spinal cord monitoring in thoracolumbar burst fractures. Spine (Phila Pa 1976) 34:2662-2668, 2009

6. Dahdaleh NS, Smith ZA, Snyder LA, Graham RB, Fessler RG, Koski TR: Lateral transpsoas lumbar interbody fusion: outcomes and deformity correction. Neurosurg Clin N Am 25:353-360, 2014

7. de Blas G, Barrios C, Regidor I, Montes E, Burgos J, PizáVallespir G, et al: Safe pedicle screw placement in thoracic scoliotic curves using t-EMG: stimulation threshold variability at concavity and convexity in apex segments. Spine (Phila Pa 1976) 37:E387-E395, 2012

8. Djurasovic M, Dimar JR II, Glassman SD, Edmonds HL, Carreon LY: A prospective analysis of intraoperative electromyographic monitoring of posterior cervical screw fixation. J Spinal Disord Tech 18:515-518, 2005

9. Donohue ML, Murtagh-Schaffer C, Basta J, Moquin RR, Bashir A, Calancie B: Pulse-train stimulation for detecting medial malpositioning of thoracic pedicle screws. Spine (Phila Pa 1976) 33:E378-E385, 2008

10. Downs SH, Black N: The feasibility of creating a checklist for the assessment of the methodological quality both of randomised and non-randomised studies of health care interventions. J Epidemiol Community Health 52:377-384, 1998

11. Esses SI, Sachs BL, Dreyzin V: Complications associated with the technique of pedicle screw fixation. A selected survey of ABS members. Spine (Phila Pa 1976) 18:2231-2239, 1993

12. Glassman SD, Dimar JR, Puno RM, Johnson JR, Shields CB, Linden RD: A prospective analysis of intraoperative electromyographic monitoring of pedicle screw placement with computed tomographic scan confirmation. Spine (Phila Pa 1976) 20:1375-1379, 1995

13. Higgins JP, Thompson SG, Deeks JJ, Altman DG: Measuring inconsistency in meta-analyses. BMJ 327:557-560, 2003

14. Hitzig SL, Eng JJ, Miller WC, Sakakibara BM: An evidencebased review of aging of the body systems following spinal cord injury. Spinal Cord 49:684-701, 2011

15. Holdefer RN, Heffez DS, Cohen BA: Utility of evoked EMG monitoring to improve bone screw placements in the cervical spine. J Spinal Disord Tech 26:E163-E169, 2013

16. Holland NR, Lukaczyk TA, Riley LH III, Kostuik JP: Higher electrical stimulus intensities are required to activate chronically compressed nerve roots. Implications for intraoperative electromyographic pedicle screw testing. Spine (Phila Pa 1976) 23:224-227, 1998

17. Legatt AD, Schroeder CE, Gill B, Goodrich JT: Electrical stimulation and multichannel EMG recording for identification of functional neural tissue during cauda equina surgery. Childs Nerv Syst 8:185-189, 1992

18. Lenke LG, Padberg AM, Russo MH, Bridwell KH, Gelb DE: Triggered electromyographic threshold for accuracy of pedicle screw placement. An animal model and clinical correlation. Spine (Phila Pa 1976) 20:1585-1591, 1995

19. Limbrick DD Jr, Wright NM: Verification of nerve root decompression during minimally-invasive lumbar microdiskectomy: a practical application of surgeon-driven evoked EMG. Minim Invasive Neurosurg 48:273-277, 2005

20. Maguire J, Wallace S, Madiga R, Leppanen R, Draper V: Evaluation of intrapedicular screw position using intraoperative evoked electromyography. Spine (Phila Pa 1976) 20:1068-1074, 1995

21. Mehta S, Orenczuk K, McIntyre A, Willems G, Wolfe DL, Hsieh JTC, et al: Neuropathic pain post spinal cord injury part 1: systematic review of physical and behavioral treatment. Top Spinal Cord Inj Rehabil 19:61-77, 2013

22. Moed BR, Ahmad BK, Craig JG, Jacobson GP, Anders MJ:
Intraoperative monitoring with stimulus-evoked electromyography during placement of iliosacral screws. An initial clinical study. J Bone Joint Surg Am 80:537-546, 1998

23. Nevzati E, Marbacher S, Soleman J, Perrig WN, Diepers M, Khamis A, et al: Accuracy of pedicle screw placement in the thoracic and lumbosacral spine using a conventional intraoperative fluoroscopy-guided technique: a national neurosurgical education and training center analysis of 1236 consecutive screws. World Neurosurg 82:866-871, 871.e1-871.e2, 2014

24. Ozgur BM, Berta S, Khiatani V, Taylor WR: Automated intraoperative EMG testing during percutaneous pedicle screw placement. Spine J 6:708-713, 2006

25. Parker SL, Amin AG, Farber SH, McGirt MJ, Sciubba DM, Wolinsky JP, et al: Ability of electromyographic monitoring to determine the presence of malpositioned pedicle screws in the lumbosacral spine: analysis of 2450 consecutively placed screws. J Neurosurg Spine 15:130-135, 2011

26. Parker SL, McGirt MJ, Farber SH, Amin AG, Rick AM, Suk I, et al: Accuracy of free-hand pedicle screws in the thoracic and lumbar spine: analysis of 6816 consecutive screws. Neurosurgery 68:170-178, 2011

27. Phillips LH II, Park TS: Electrophysiological monitoring during lipomyelomeningocele resection. Muscle Nerve 13:127-132, 1990

28. Quiñones-Hinojosa A, Gadkary CA, Gulati M, von Koch CS, Lyon R, Weinstein PR, et al: Neurophysiological monitoring for safe surgical tethered cord syndrome release in adults. Surg Neurol 62:127-135, 2004

29. Raynor BL, Lenke LG, Bridwell KH, Taylor BA, Padberg AM: Correlation between low triggered electromyographic thresholds and lumbar pedicle screw malposition: analysis of 4857 screws. Spine (Phila Pa 1976) 32:2673-2678, 2007

30. Raynor BL, Lenke LG, Kim Y, Hanson, DS, Wilson-Holden TJ, Bridwell KH, et al: Can triggered electromyograph thresholds predict safe thoracic pedicle screw placement? Spine (Phila Pa 1976) 27:2030-2035, 2002

31. Regidor I, de Blas G, Barrios C, Burgos J, Montes E, GarcíaUrquiza S, et al: Recording triggered EMG thresholds from axillary chest wall electrodes: a new refined technique for accurate upper thoracic (T2-T6) pedicle screw placement. Eur Spine J 20:1620-1625, 2011

32. Reidy DP, Houlden D, Nolan PC, Kim M, Finkelstein JA: Evaluation of electromyographic monitoring during insertion of thoracic pedicle screws. J Bone Joint Surg Br 83:10091014, 2001

33. Rodriguez-Olaverri JC, Zimick NC, Merola A, De Blas G, Burgos J, Piza-Vallespir G, et al: Using triggered electromyographic threshold in the intercostal muscles to evaluate the accuracy of upper thoracic pedicle screw placement (T3-T6). Spine (Phila Pa 1976) 33:E194-E197, 2008

34. Samdani AF, Tantorski M, Cahill PJ, Ranade A, Koch S, Clements DH, et al: Triggered electromyography for placement of thoracic pedicle screws: is it reliable? Eur Spine J 20:869-874, 2011

35. Shi YB, Binette M, Martin WH, Pearson JM, Hart RA: Electrical stimulation for intraoperative evaluation of thoracic pedicle screw placement. Spine (Phila Pa 1976) 28:595-601, 2003

36. Silverstein JW, Mermelstein LE: Utilization of paraspinal muscles for triggered EMG during thoracic pedicle screw placement. Am J Electroneurodiagn Technol 50:37-49, 2010

37. Tohmeh AG, Rodgers WB, Peterson MD: Dynamically evoked, discrete-threshold electromyography in the extreme lateral interbody fusion approach. J Neurosurg Spine 14:3137, 2011

38. Toleikis JR, Skelly JP, Carlvin AO, Toleikis SC, Bernard TN, Burkus JK, et al: The usefulness of electrical stimula- 
tion for assessing pedicle screw placements. J Spinal Disord 13:283-289, 2000

39. Viswanathan M, Ansari MT, Berkman ND, Chang S, Hartling L, McPheeters M, et al: Assessing the risk of bias of individual studies in systematic reviews of health care interventions, in Methods Guide for Effectiveness and Comparative Effectiveness Reviews. Rockville, MD: Agency for Healthcare Research and Quality, 2008

40. von Koch CS, Quinones-Hinojosa A, Gulati M, Lyon R, Peacock WJ, Yingling CD: Clinical outcome in children undergoing tethered cord release utilizing intraoperative neurophysiological monitoring. Pediatr Neurosurg 37:81-86, 2002

41. Wang MY, Pineiro G, Mummaneni PV: Stimulus-evoked electromyography testing of percutaneous pedicle screws for the detection of pedicle breaches: a clinical study of 409 screws in 93 patients. J Neurosurg Spine 13:600-605, 2010

42. Welch WC, Rose RD, Balzer JR, Jacobs GB: Evaluation with evoked and spontaneous electromyography during lumbar instrumentation: a prospective study. J Neurosurg 87:397402, 1997

43. Wu AM, Zhou Y, Li QL, Wu XL, Jin YL, Luo P, et al: Interspinous spacer versus traditional decompressive surgery for lumbar spinal stenosis: a systematic review and meta-analysis. PLoS One 9:e97142, 2014

44. Zamora J, Abraira V, Muriel A, Khan K, Coomarasamy A:
Meta-DiSc: a software for meta-analysis of test accuracy data. BMC Med Res Methodol 6:31, 2006

\section{Disclosures}

Dr. Anderson has ownership in SI Bone, Expanding Orthopedics, Titan Spine, and Spartec; is a consultant for Aesculap and Stryker; and holds patents for Stryker and RTI. Dr. Williams is a consultant for DePuy Synthes Spine.

\section{Author Contributions}

Conception and design: Anderson, Mikula. Acquisition of data: Mikula. Analysis and interpretation of data: Anderson, Mikula. Drafting the article: Anderson, Mikula. Critically revising the article: all authors. Reviewed submitted version of manuscript: all authors. Approved the final version of the manuscript on behalf of all authors: Anderson. Statistical analysis: Anderson, Mikula. Study supervision: Anderson.

\section{Correspondence}

Paul A. Anderson, Department of Orthopedics and Rehabilitation, University of Wisconsin School of Medicine and Public Health, UWMF Centennial Building, 1685 Highland Ave., 6th Fl., Madison, WI 53705. email: anderson@ortho.wisc.edu. 